\title{
De la historia de las ideas a la nueva historia intelectual: Retrospectivas y perspectivas. Un mapeo de la cuestión
}

\author{
Mariano A. Di Pasquale $\left(^{*}\right)^{1}$
}

\section{RESUMEN}

Elobjeto de este artículo es proporcionar una mirada más cercana a las tendencias actuales de la Historia Intelectual. El presente trabajo surge del análisis de la incertidumbre epistemológica actual en las Ciencias Sociales. También, se observa el desplazamiento de la Historia de las Ideas y de la Historia de las Mentalidades hacia una Historia de los Lenguajes Políticos. Finalmente, se sintetizan los rasgos centrales y se evidencian una serie de dilemas y nuevos desafíos planteados a partir de la recepción del denominado Giro Lingüístico en este campo de estudios particular de la historia.

Palabras clave:

Historia de las ideas - historia intelectual - giro lingüístico.

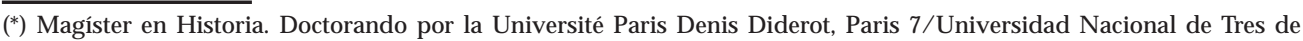
Febrero, Argentina. Becario CONICET.

Artículo recibido el 20 de agosto de 2010. Aceptado por el Comité Editorial el 11 de abril de 2011.

Correo electrónico: marianodipasquale@gmail.com

1 * El autor agradece especialmente a Jaime Peire por sus comentarios y sugerencias como así también a Mariano Plotkin, Marcela Ternavasio y Marcelo Summo.
} 


\begin{abstract}
The purpose of this article is to provide a closer look at the current trends in Intellectual History. This work stems from the analysis of epistemology uncertainties in the Social Sciences. In addition, the History of the ideas and mentalities have been displaced by the History of political languages. Finally, the central features, are synthesised and show a series of, dilemmas and news challenges to this particular field of historical study posed by the reception of the Linguistic Turn.
\end{abstract}

Key words:

History of ideas - intellectual history - linguistic turn.

\title{
Introducción
}

En los últimos veinte años la historia intelectual experimentó un desarrollo creciente y dinámico en el campo historiográfico. Esta productividad de estudios generó una serie de transformaciones de las categorías teóricas existentes y una pluralidad de criterios metodológicos. Tal es así, que cada historiografía nacional diseñó su propia conceptualización y, en cada una de ellas, se fueron articulando distintas nociones explicativas, apenas diferenciables unas de otras, que como -explica Roger Chartierentraron en una competencia académica por imponerse una sobre otra ${ }^{1}$.

En las investigaciones actuales observamos cada vez con mayor notoriedad el escaso empleo y aplicación de las categorías "ideas", "ideologías", "mentalidades". En reemplazo el lector encuentra la utilización de términos tales como "discursos", "lenguajes" y / o "conceptos". Esta mutación de significados implica una diferenciación de abordajes y un conjunto de redefiniciones fundamentales, por las cuales las nuevas tendencias de la historia intelectual van a distinguirse de la tradicional "historia de las ideas".

El reemplazo se hace visible por ejemplo cuando se cotejan los trabajos de Lucien Febvre con los de Quentin Skinner con respecto a la vida y obra de Martín Lutero y el protestantismo. Así también resulta diferente el "Maquiavelo" que reconstruye Sheldon Wolin con respecto al que presenta John Greville Agard Pocock. Existen claves interpretativas muy disímiles en torno al proceso de independencias americanas y la problematización de la recepción de la Ilustración y su posible fuerza en dicho proceso en la visión que ofrece Manfred Kossock de la que nos llega a través de los estudios de François-Xavier Guerra o Anthony Pagden.

Es pertinente preguntarnos, pues, ¿por qué se produce este salto? ¿cómo se origina

\footnotetext{
${ }^{1}$ Chartier, R. El mundo como representación. Historia cultural: entre práctica y representación, Gedisa, Barcelona, 2002, p.14.
} 
este corrimiento? ¿qué consecuencias ocasiona? ¿cuáles son las tendencias actuales que existen y cuál de todas ellas es la que se impone por sobre las otras generando un modelo inteligible? Estos cuestionamientos orientan el presente artículo. Y expreso "orientan" porque nos ubican ante un nudo de problemas pertinentes a nuestro objeto de análisis pero que, en esta instancia, resultan de difícil aproximación por su magnitud y complejidad.

A cambio se propone reformular dichas incertidumbres planteando otro tipo de interrogante plausible de ser respondida: ¿de qué modo y bajo qué condiciones se produce esta sustitución de categorías en el uso cotidiano de los que se dedican a la historia en general, y específicamente, los que se ocupan de la historia de las ideas? Cabe resaltar que el desplazamiento semántico se produce en el contexto emergente del denominado Giro Lingüístico producido en las ciencias sociales y humanas ${ }^{2}$. Su impacto es visible en los estudios culturales, políticos e históricos al instalar la cuestión del lenguaje como un hecho insoslayable.

A modo de hipótesis, se busca demostrar que existe un alejamiento de la tradicional Historia de las ideas con un tipo de abordaje cifrado en los contenidos intelectuales hacia una nueva Historia intelectual que prioriza las formas en las cuales los pensamientos se inscriben y se reproducen socialmente en un determinado espacio y tiempo. En este sentido, el propósito estriba en mapear el tránsito de estos cambios e identificar los nuevos perfiles y lógicas implicadas en la dinámica de la denominada, lato sensu, historia de las ideas.

\section{Una historia intelectual de la autoconciencia: una retrospectiva centrada en los contenidos intelectuales}

Eric Cochrane ha señalado la existencia de dos dimensiones explicativas para abordar las diversas corrientes de pensamientos a principios del siglo $X^{3}$. Por aquellos años, los pensadores y los movimientos intelectuales eran objeto de estudio de las denominadas "historias del pensamiento" y las "historias de la filosofía".

En el primer caso, se planteaba un enfoque que establecía una estrecha relación entre los pensadores "clásicos" y sus producciones textuales más representativas. Esta operación proporcionaba al investigador la posibilidad de analizar un corpus bibliográfico identificando y examinando los contenidos o temáticas centrales latentes en los pensadores a través de sus escritos más destacados. En general, se establecía

\footnotetext{
2 Sin ánimo de ser exhaustivo remitirse a Rorty, R., El giro lingüístico: dificultades metafilosóficas de la filosofía lingüística, Paidós, Barcelona, 1990; Vallespín, F., "Giro Lingüístico e historia de las ideas: Q. Skinner y la escuela de Cambridge" en Aramayo, Roberto; Muguerza, Javier y Valdecantos, Antonio (comp.). El individuo y la historia. Antinomias de la herencia moderna, Paidós, Barcelona, 1995, pp. 287-301; Chartier, R. "La historia hoy en día: dudas, desafíos, propuestas" en Olábarri, I. y Caspistegui, F. J. La Nueva Historia Cultural: la influencia del postestructuralismo y el auge de la interdisciplinariedad. Cursos de verano de El Escorial, Ed. Complutense, Madrid, 1996, pp. 21-33; Palti, Elías, Giro Lingüístico e Historia Intelectual. Universidad de Quilmes, Quilmes, 1998; Dosse, François, La marche des idées. Histoire des intellectuels. Histoire intellectuelle, Éditions La découverte, París, 2003.

${ }^{3}$ Cochrane, E. "Historia de las ideas e historia de la cultura" en La historiografía en Occidente desde 1945, III Conversaciones Internacionales de Historia, Navarra, 1995, pp. 131-148.
} 
una línea que se dedicaba a realizar una exégesis de las obras principales. Estos textos en alguna medida constituían una herencia en el pensamiento moderno porque, entre otras cuestiones, estos sistemas de ideas se traslucían en los diseños políticos e institucionales actuales. La historia del pensamiento humano quedaba reducida a una especie de biografía del pensamiento. Tal maniobra analítica dejaba de lado el contexto social de producción de los textos. Estos sólo se analizaban en cuanto que constituían un "canon" que bajo el rótulo de "textos clásicos" interesaban a la luz que posibilitaban la comprensión y el establecimiento de una continuidad temporal con el presente.

Las historias de la filosofía, en cambio, accedían al estudio de las ideas a través de los sistemas, escuelas o movimientos; así, por ejemplo, estudiaba el idealismo alemán, al racionalismo francés, al empirismo inglés, y no a Hegel, Descartes o Locke. La desventaja de tal enfoque radicaba en concebir a estos movimientos filosóficos como irreductibles, cerrados en sí mismos, sin conexiones posibles, fuera de la realidad social. En efecto, ambas visiones priorizaban un estudio configuracional del pensamiento racional apoyándose en el análisis de los grandes textos u obras fundacionales. En alguna medida, estas apreciaciones colocaban en segundo plano los rasgos del contexto social y la articulación entre una determinada corriente intelectual y la cultura que lo daba a nacer.

Contra estas dos visiones tradicionales se dieron dos reacciones que pusieron en evidencia la ausencia del componente histórico y social en el análisis de los pensamientos. La primera se originó en el continente americano, y tomó como nombre History of ideas, fue impulsada principalmente por Arthur Lovejoy. La segunda, apareció en Europa continental, Francia, y se denominó Historie des mentalités, originada en los estudios de la Escuela de los Annales, a partir de las líneas de investigación que impulsaron los trabajos pioneros de Lucien Febvre y Marc Bloch.

La History of ideas enfocaba su abordaje a partir del concepto de ideas-elementos o ideaunidad. Esto es, aquellos elementos constitutivos en sí de un sistema filosófico dado que permite -en alguna medida- realizar nuevos agrupamientos y relaciones entre los hombres y las ideas. Esta escuela partía de la noción de rastrear ciertos filosófemas o núcleos de ideas a través de criterios de selección que podían ser el de generalidad, continuidad, especificidad, etc. Un ejemplo de dicha aproximación lo constituye la obra de Robert Nisbet, La formación del pensamiento sociológico, texto publicado en 1966. Aquí el autor traza una historia del pensamiento sociológico a partir de las siguientes ideas-elementos: comunidad, autoridad, estatus, lo sacro y alienación ${ }^{4}$.

En esta perspectiva, las ideas -sobre todo se ponía el acento en el estudio de aquellas derivadas del pensamiento político-, eran un marco de referencia, una categoría, donde los hechos y las concepciones formaban una unidad indisoluble. A su vez, consideraba que las ideas poseían una dimensión dinámica, trazaban un recorrido, un tránsito. Revestían un espesor social, un "espacio" en donde se trasladan de

${ }^{4}$ Nisbet, R. La formación del pensamiento sociológico, 2 tomos, Buenos Aires, Amorrortu, 2003. 
una cultura a otra, de una época a otra, dando así una multiplicidad de sentidos y "relieves" superpuestos de significados.

Para Arthur Lovejoy, un historiador de las ideas debía demostrar una capacidad para “...el discernimiento y análisis de conceptos y un ojo avezado para las relaciones lógicas o las afinidades cuasi lógicas no inmediatamente obvias entre ideas" Desde el registro metodológico, la Historia de las ideas se presentó como un campo abordado por un abanico de visiones complementarias: se definía en el ámbito de la interdisciplinariedad.

El otro enfoque, no solo se constituyó como otro modelo explicativo en torno al fenómeno del análisis del pensamiento, sino que también propuso otra semántica para definir su objeto de estudio: mentalités. La Historia de las mentalidades nació como respuesta a la crisis de valores ideológicos y morales producida por las consecuencias del mundo de entreguerras. En este sentido, presentó un deseo por responder a ciertas preguntas invocando al pasado para entender un presente derrumbado y fragmentado -en su más íntimo ser- por la Gran Guerra. Problemáticas tales como la ausencia de Dios, el sentido de la vida y la muerte, la presencia del amor, lanzaron interrogantes hacia un pasado no tan lejano: ¿qué pensaban y qué creían sus antepasados? ¿cómo lo hacían? ¿qué cantidad de hijos tenían? ¿cómo era la vida del hombre "común"? ¿cuáles y cómo eran las alegrías, angustias, miedos?

La historiografía francesa, específicamente la denominada Escuela de los Annales, fue la que condujo las primeras respuestas quizás por la acumulación de varias tradiciones previas. La difusión de la sociología de corte naturalista, en especial la noción suministrada por Emile Durkheim de "conciencia colectiva", inspiró a los primeros historiadores de este movimiento a incorporar el aspecto social como un fenómeno imprescindible para comprender las mentalidades.

Frente a la irreductibilidad del planteo de las ideas-unidad de Lovejoy, la Historia de las mentalidades se direccionaba a analizar todos los niveles de la sociedad, en tanto, se preocupaba por entender las concepciones de sectores sociales relegados. La centralidad estaba puesta en el conjunto de los sujetos históricos y sus sentidos del mundo constituyendo un abordaje que enfatizaba una "estructura mental colectiva".

Sin embargo, este conjunto de trabajos prefiguró la tesis que después Duby desarrollará en el libro más significativo e influyente en el campo de la historia de las mentalidades: Les trois ordres ou l'imaginaire du féodalisme ${ }^{6}$. Esta obra tiene como propósito estudiar la articulación de la estructura social en la época feudal con la "superestructura" ideológica. Duby abrió la puerta de un abordaje estructuralista aplicado a los estudios de la mentalidad en el Norte de Francia. Esta investigación radicó en un análisis de la sociedad feudal a través de numerosos documentos y

${ }^{5}$ Lovejoy, A. "Reflexiones sobre la historia de las ideas", Prismas, Revista de Historia Intelectual, Universidad Nacional de Quilmes, Quilmes, Vol. IV, 2000, p. 129.

${ }^{6}$ Duby, G. Les trois ordres ou l'imaginaire du féodalisme. Gallimard, París, 1978 (trad. cast.: Los tres órdenes o el imaginario del feudalismo, Petrel, Barcelona, 1980). 
autores prácticamente abandonados. Apoyado en esas fuentes, Duby planteó que el orden feudal se fundamentó en un imaginario que concebía a la sociedad como una estructura basada en tres tipos de actores sociales con una función muy clara: los monjes y el discurso; los caballeros nobles y la defensa; y los comerciantes y campesinos y la producción. Es decir, demostraba la existencia de una trifuncionalidad en dicha sociedad: los que oran (piensan), los que guerrean (gobiernan) y los que trabajan (producen). En tanto, es que el autor trata de "vincular fuertemente las representaciones colectivas y las conductas personales al estado de una sociedad, es decir, a su historia"7.

El aporte de la psicología social a la historia colectica de las mentalidades fue también decisiva en su desarrollo llevando a determinar, por ejemplo, usos de metodologías y técnicas estadísticas y exactas para estandarizar las fuentes utilizadas. El método serial y cuantitativo, extraído de la demografía y la historia económica, resultó primordial. La Historia de las mentalidades

"no ha dudado en explotarlo con la ayuda de computadoras: este único medio de sacar todo el jugo y todas las correlaciones de documentos bastante homogéneos para constituir corpus, y a la vez verdaderamente masivos, como las 50.000 relaciones de causas de la Inquisión española o las 15.000 de la portuguesa o las matrículas de recluta"'.

Años más tarde, se presenció una disputa entre los seguidores de la idea-unidad y los que abogaban por las estructuras mentales. Roger Chartier expresa esta situación cuando indica que durante la década de 1960

"se constituye en objeto histórico fundamental un objeto que es diametralmente opuesto al de la historia intelectual clásica: frente a la idea, construcción consciente de un espíritu individualizado, se opone, la mentalidad siempre colectiva que regula, sin explicarse, las representaciones y los juicios de los sujetos en sociedad"9.

\section{Ideas y mentalidades en el contexto de tránsito}

A fines de 1970 y durante la década de 1980 emergió una atmósfera de preocupación que se presentó en las ciencias sociales como reflejo del grado de fragilidad expuesto por la pérdida de ciertos "controles argumentativos". Muchos investigadores sociales establecieron diversos cuestionamientos $\mathrm{y}$, al mismo tiempo, crearon un espacio nuevo de reflexión y/o exploración del mundo en las ciencias sociales ${ }^{10}$. Pronto, comenzó a desplegarse una multiplicidad de críticas sobre el "dogma logicista" que daba sustento a los mecanismos conceptuales y argumentativos de las relaciones del conocimiento.

Al respecto, uno de los discursos más críticos, en su momento, fue el presentado por Michel Foucault. Este se autopreguntaba: “qué idea se hace usted del cambio,

${ }^{7}$ Duby, G. "Historia de las mentalidades", en Rojas, B. (comp.), Obras selectas de Georges Duby, F.C.E, México, 1999 , p. 47. ${ }^{8}$ Bennassar, B. "Historia de las mentalidades", en Vázquez de Prada, V.; Olábarri, I. y Caspistegui, F., Para comprender el cambio social. Enfoques teóricos y perspectivas historiográficas, Pamplona, 1997, p. 160.

${ }^{9}$ Chartier, R. El mundo como representación..., Op. cit., p. 23.

${ }^{10}$ Bourdieu, P. El oficio de científico. Ciencia de la ciencia y reflexividad. Anagrama, Barcelona, 2003; Chartier, R. El mundo como representación..., Op. cit, pp. 45-62; Foucault, M., El orden de los discursos. Tusquets, Buenos Aires, 2004. 
y digamos de la revolución, al menos en el orden científico y en el campo de los discursos, si la liga usted a los temas del sentido, del proyecto, del origen y del retorno, del sujeto constituyente, en suma, a toda la temática que garantiza a la historia la presencia universal del Logos?"11. En efecto, Foucault proponía una profunda revisión de los criterios enunciativos y discursivos de las ciencias. Sin embargo, estas objeciones no son aisladas: se producen a lo largo de todo el siglo XX. Sólo basta mencionar a Sigmund Freud, Ferdinand Saussure, Jean Paul Sartre, Maurice MerlotPonty, Claude Levy-Strauss, Antonio Gramsci, Jacques Lacan, entre otros. Todos ellos pueden interpretarse como un caleidoscopio de censura progresiva hacia los pilares de la ciencia moderna.

Estas voces alternativas comenzaron a mostrar que el problema principal estribaba en la ruptura de la relación gnoseológica en la cual el sujeto era "condición de posibilidad" que lo facultaba para distinguir los objetos del mundo, fijarlos y ubicarlos en relación entre sí. La manera de abordar y aprehender el mundo era concebida en términos propios como causa de la conciencia. El diseño científico establecido en la "modernidad" a partir del "canon kantiano" entre objeto y sujeto de conocimiento dejaba de ser plausible desde entonces, produciendo una fragmentación de este paradigma fundamental que, otrora, generaba el sustento de la viabilidad científica y el criterio de verdad a la hora de emprender una actividad investigativa. Hubert Dreyfus y Paul Rabinow explican que

la interpretación kantiana introduce la noción de que el hombre es el único ser que está totalmente implicado en la naturaleza (su cuerpo), la sociedad (relaciones históricas) y el lenguaje (su lengua materna) y que, al mismo tiempo, encuentra un firme fundamento para todas estas formas de vinculación en los significados que les otorga ${ }^{12}$.

La heredera de esta concepción en el siglo XX fue la fenomenología, ya que ésta implica para sus estudios el acceso directo e inmediato de los hechos a la conciencia ${ }^{13}$. Por otro lado, la <verdad científica objetiva $>$, fue liberada de su precepto positivista a partir de la crítica, considerándola una construcción cultural en movimiento permanente ${ }^{14}$. Le sigue a esto, según Chartier "una desaparición de los modelos de comprensión, de los principios de inteligibilidad que habían sido comúnmente aceptados por los historiadores (o por la mayoría de ellos) desde los años setenta"15.

Los esquemas estructuralistas, los enfoques marxistas y las metodologías cuantitativas se encontraron paulatinamente bajo una mirada analítica -muchas veces- objetivada por una crítica intensa y aguda. Los criterios de inteligibilidad de las ciencias sociales que otorgaban unidad a sus objetos y a sus avances se vieron agotados en proveer a los

\footnotetext{
${ }^{11}$ Foucault, M. La Arqueología del Saber, Siglo Veintiuno Editores, Buenos Aires, 2002, p. 352.

${ }^{12}$ Dreyfus, H. y Rabinov, P. Michel Foucault: más allá del estructuralismo y la hermenéutica, Nueva Visión, Buenos Aires, 2001, p. 17.

${ }^{13}$ Waldenfels, B. De Husserl a Derrida. Introducción a la fenomenología, Paidós, Barcelona, 1992, p. 35.

${ }^{14}$ Ankersmit, F.R. “La verdad en la literatura y en la historia” en Olábarri, I. y Caspistegui, F. La Nueva Historia Cultural..., Op. cit., pp. 49-57.

${ }^{15}$ Chartier, R. "La historia hoy en día: dudas, desafíos, propuestas" en Olábarri, I. y Caspistegui, F. La Nueva Historia Cultural..., Op. cit, p. 20.
} 
investigadores sociales herramientas conceptuales para deducir posibles respuestas y -sobre todo- encontrar certezas argumentativas.

El mundo del conocimiento ordenado y sostenido estalló caóticamente en un sin fin de aspectos instalando el debate entre el perspectivismo y el relativismo ${ }^{16}$. En otras palabras, se propone desnaturalizar el objeto de estudio de las ciencias sociales, y revisar la noción de que esos objetos de estudio -en nuestro caso, las ideas-unidad y las mentalidades- se comporten de forma autónoma y sean aprensibles totalmente por la racionalidad del investigador. Chartier comenta que

La historia intelectual no debe dejar engañarse por palabras que pueden dar la ilusión de que los distintos campos de discurso o de prácticas están constituidos de una vez para siempre, desglosando objetos cuyos contornos, si no los contenidos, no varían; contrariamente, ésta debe plantear como centrales las discontinuidades que hacen que se designen, se agreguen y se ventilen, en formas diferentes o contradictorias según las épocas, los conocimientos y las acciones ${ }^{17}$.

A finales de la década de 1970 la Historia de las ideas y la Historia de las mentalidades -esgrimidas sobre las bases del estructuralismo y la fenomenología- presentaron una serie de lagunas conceptuales ante la formulación de una nueva premisa: la aproximación a un "objeto intelectual" no podía entenderse como un "objeto natural" o un "objeto racional dado". Se hizo insoslayable que tanto la noción de idea-unidad como las mentalités no se ordenaban exclusivamente dentro del campo racional sino que muchas veces eran parte de una fuerza irracional y, por lo tanto, de difícil acceso.

Es por esto que a partir de producción historiográfica de la década de 1980 aparecieron distintos desplazamientos conceptuales a fin de solucionar "potencialmente" -y en parte- dicho tiempo de incertidumbre. En el caso de la ciencia histórica, estas nuevas miradas se presentaron desde otros espacios del saber. Los cuestionamientos vinieron de otras dimensiones analíticas ya que la misma parecía estar encerrada dentro de sus propias lógicas internas.

La lingüística, el psicoanálisis, la crítica literaria, la hermenéutica y la antropología, constituyeron las flamantes perspectivas que tomaron los historiadores en pos de resolver -a su manera- ese "espacio de incertidumbre epistemológico" dejado por las paradojas de los modelos explicativos anteriores. Este hecho revela una nueva situación que se plantea a los investigadores sociales actuales como un acontecimiento irreversible: cualquier análisis humanístico debe ser integrado desde una pluralidad de herramientas conceptuales, dando prioridad al enfoque interdisciplinario.

En el área particular de la Historia de las ideas y la Historia de las mentalidades, la "crisis gnoseológica" originó la búsqueda de nuevos elementos para flexibilizar los obstáculos encontrados en ambas tradiciones. Las preguntas se fueron articulando en torno a otras problemáticas y, por lo tanto, los nuevos desafíos establecieron otras aproximaciones. ¿Cómo reflexionar sobre el objeto intelectual-ideas y / o mentalidades-

${ }^{16}$ Geertz, C. Reflexiones antropológicas sobre temas filosóficos, Paidós, Barcelona, 2002, p. 141.

${ }_{17}$ Ídem, p. 42. 
que se percibió desplazado de lugar? ¿Cómo operar metodológicamente sobre las nuevas preguntas lanzadas desde otras problemáticas? En definitiva ¿cómo debería reconstruirse -según estas exigencias- el discurso histórico y qué posición adoptaría el investigador ante las fuentes utilizadas para componer el pasado?

La "nueva historia intelectual" emerge en este contexto de tránsito y crisis de las ciencias sociales. Esta constituye un abanico de herramientas y modos de aproximación que proponen dar posibles respuestas a las encrucijadas anteriores. De alguna manera, intenta reconstruir un objeto de estudio puesto en jaque, estableciendo modelos teóricos que se proyectan hacia distintos niveles de análisis en las construcciones, sentidos y condiciones del pensamiento del hombre.

\section{Hacia una historia intelectual de los lenguajes: perspectivas de una historia de las formas intelectuales}

La historia intelectual reciente, entonces, recibe un nuevo desafío: el estudio de las formas del lenguaje como el lugar central de construcción de los significados, dejando de lado esa noción que unía a todas las variantes anteriores que era el pensar sobre un campo de objetos-sujetos aprehensibles por la autoconciencia. El estudio del lenguaje como centro de la nueva historia intelectual refleja una de las propuestas de re-significar las construcciones positivas en la investigación histórica.

Más allá de las diferencias entre las distintas corrientes lingüísticas que confluyen en la historia intelectual existe un punto en común en los nuevos posicionamientos: el rechazo directo a la filosofía del sujeto tradicional. La base conceptual radica en la "... preexistencia de un campo simbólico ya organizado, una estructura de significados, lo que nos faculta para articular nuestros pensamientos y percepciones"18. En otras palabras, el instrumento por el cual se opera intelectualmente -esto es, la razón o la conciencia- se halla inmerso en una red de significados previamente establecidos -codificados- que dan sentido a las acciones del individuo. Siguiendo a Gerome Bruner, existe cierto orden a partir del cual pensamos ${ }^{19}$.

Los estudios sobre las teorías del lenguaje pueden rastrearse tiempo atrás, aunque, es a partir del calificado Giro Lingüístico donde las mismas cobran centralidad en las nuevas perspectivas de la historia intelectual ${ }^{20}$. La característica fundamental de estos esquemas es la reducción de la percepción del mundo y el hombre a su lingüisticalidad ${ }^{21}$. Actualmente, el planteamiento remite a los objetos lingüísticos, más precisamente, al lenguaje como elaboración de los sentidos. Ahora bien, ¿cuáles son los lineamientos o los rasgos principales del Giro Lingüístico y qué impacto produce

${ }^{18}$ Vallespín, F. “Giro Lingüístico e historia de las ideas...", Op. cit., p. 288.

${ }^{19}$ Bruner, G. Realidad mental y mundos posibles. Los actos de la imaginación que dan sentido a la experiencia, Gedisa, Barcelona, 1998.

${ }^{20}$ Este término fue expresado por primera vez por Gustav Bergmann, pero fue difundido por Richard Rorty. Véase Rorty, R. El giro lingüístico..., Op. cit. En nuestro caso, es utilizado en un <sentido amplio> dando a entender, no sólo el recorrido de las distintas apreciaciones de los autores de este movimiento intelectual, sino el fundamento básico que evidencia que nuestra aproximación al conocimiento "gira" en torno al carácter lingüístico.

${ }^{21}$ Gadamer, H. G. Mito y Razón, Barcelona, Paidós, 1997, pp. 67-81. 
en esta área específica de la ciencia histórica?

Los efectos de este movimiento se aprecian en investigadores de círculos más amplios. Al respecto, es notable la gravitación del pensamiento de Clifford Geertz. Este considera que el mundo actúa siempre en nosotros al ser conformados culturalmente ${ }^{22}$. Geertz explica que el sujeto es considerado como el resultado del cúmulo de experiencias culturales que lo orientan en sus apreciaciones y en sus conductas individuales. Estas vivencias sólo pueden ser aprehensibles por el investigador en los niveles discursivos, puesto que ellos, en alguna medida, reflejan los modos argumentativos del pensamiento. El objeto de estudio que puede ser comprendido es el lenguaje ya que en él se expresan las disposiciones mentales de los individuos ${ }^{23}$. Todo acontecimiento social se articula en el "hecho lingüístico".

La inmersión del sujeto en la historia se encuentra lingüísticamente mediada y sólo deviene como inteligible cuando se produce una operación de decodificación del lenguaje ${ }^{24}$. En consecuencia, el desarrollo de los estudios textuales y literarios cobra un rol fundamental, tanto en las metodologías de la investigación histórica como en las maneras de presentar -narrar- los tiempos de la historia ${ }^{25}$.

En la misma dirección, tanto Fernando Vallespín como Peter Burke, exponen la existencia de tres tradiciones de estudios lingüísticos que son -en parte- los que contribuyen a la formación de la "nueva historia intelectual" 26 . La primera, deriva de la tradición francesa, especialmente de las obras de Ferdinand Soussure, Michell Foucault, Paul Ricoeur, Jacques Derrida, Gilles Delueze, todos ellos -dejando arriesgadamente las diferencias de lado- suministran una lectura semiológica y ponen el acento en comprender los distintos dispositivos narrativos que se usan por lo común en la ciencia historia, trazando el desarrollo de una "historia de los discursos políticos" 27 . Los discursos son comprendidos como modos de acción e interacción social, ya que ubicados en contextos sociales, los participantes no son tan sólo hablantes/escribientes y oyentes/lectores, sino también actores sociales que actúan como miembros de grupos y culturas políticas. En consecuencia, los discursos son espacios sociales que reflejan las representaciones de dichos actores y, por tanto, siempre recorren una intencionalidad, ya sea la legitimación de cierto orden político o la resistencia a un nuevo modelo social. Lo expresa bien Foucault cuando indica que "en toda sociedad la producción del discurso está a la vez controlada, seleccionada y redistribuida por ciertos mecanismos o procedimientos que tienen como función legitimar relaciones de poder, y por ende, buscar persuadir socialmente las prácticas políticas" ${ }^{\prime \prime 2}$. En el ámbito historiográfico actual, se puede incluir en esta línea a Pierre Rosanvallon, François Dosse, entre otros.

\footnotetext{
${ }^{22}$ Geertz, C. La interpretación de las culturas, Gedisa, Barcelona, 1988.

${ }^{23}$ Gadamer, H. G. El giro hermenéutico, Cátedra, Madrid, 1998.

${ }^{24}$ Derrida, J. La desconstrucción en las fronteras de la filosofía. La retirada de la metáfora, Paidós, Barcelona, 1998.

${ }^{25}$ Para analizar dos visiones heterogéneas sobre esta cuestión comparar las apreciaciones de Koselleck, R. Futuro Pasado. Para una semántica de los tiempos históricos, Paidós, Barcelona, 1993 y Ricoeur, P., Tiempo y narración, 3 vols., Gedisa, Barcelona, 1994.

${ }^{26}$ Vallespín, F. "Giro Lingüístico e historia de las ideas...", Op. cit, p. 289; Burke, P., Hablar y Callar. Funciones sociales del lenguaje a través de la historia, Gedisa, Barcelona, 2001, pp. 16-17.

${ }^{27}$ Dosse, F. La marche des idées..., Op. cit.

${ }^{28}$ Foucault, M. El orden..., Op. cit, p. 14.
} 
La segunda tradición proviene de Alemania, donde coexisten dos perspectivas. La primera, proviene de los estudios de Martín Heidegger, Jurgen Habermas y HansGeorge Gadamer, y propician lo que se conoce como "enfoque hermenéutico" ${ }^{29}$. La segunda, con un impacto más relevante en el campo historiográfico, surge a partir de las consideraciones de Reinhart Koselleck, tomando como nombre la "historia de los conceptos". Este enfoque estriba en definir el Begriff (concepto) como el significado de una palabra, dando a entender algo que se expone "fuera" del lenguaje ${ }^{30}$. Tal propuesta distingue "las palabras" de los "conceptos" ${ }^{31}$. Una "palabra" tiene muchos significados en general, pero no tiene más que un significado en cada contexto o situación. En cambio, un "concepto" siempre aparece como un término ambiguo o polisémico, en cualquier contexto que se presente. Por ello, pone en evidencia la historicidad y la larga duración en el análisis del pensamiento político. Koselleck introduce el concepto de Sattelzeit: un tiempo entre dos eras, una época entre los dioses muertos y los nuevos. Este momento de transición se inscribe entre 1750-1850, entre Montesquieu y Marx. Para el autor, antes de 1750 los cambios que se producen en el pensamiento son graduales, y éstos se observan muy lentamente en los vocabularios y los lenguajes, pero luego, con el derrumbe del absolutismo, el hombre busca nuevos conceptos y, recién en este punto, el tiempo se acelera y las transformaciones producidas en la semántica se vuelven dinámicas y más complejas de detectar.

Por último, se encuentra la tradición anglosajona, que parte de las ideas de Wittgenstein, y continúa con las indagaciones de John Austin, John Greville Agard Pocock, Quentin Skinner, Anthony Pagden, y otros. Esta corriente en general denominada Escuela de Cambridge, impulsa la "historia de los lenguajes políticos" ${ }^{\prime 32}$. Para esta escuela, los textos son considerados como actos de habla, en tanto, se distingue un nivel locutivo de un enunciado y su fuerza ilocutiva, es decir, se diferencia lo que se dice y lo que se hace al decirlo ${ }^{33}$. Esta consideración es de suma importancia porque otorga al lenguaje un espacio de acción y un proceso performativo en el medio social y cultural en el cual se desenvuelve. El lenguaje es entendido como un objeto de estudio activo que puede ir modelando e interactuando con el medio social. De la misma manera, es necesario comprender ese acto de habla dentro de un escenario de relaciones lingüísticas para lograr percibir la intencionalidad del actor social, qué acción emprendió éste al decir lo que decía en el contexto en que lo llevo a cabo ${ }^{34}$. Así pues, el texto cobra pertinencia en un contexto específico. La escuela de Cambridge pone su atención en el análisis de los lenguajes puestos en circulación a través de las controversias y los intercambios narrativos producidos en determinados contextos. Se pregunta fundamentalmente cómo un autor dialoga con los problemas políticos de la época. Esto le permitiría al

${ }^{29}$ Para profundizar este asunto, remitirse a Grondin, J. Introducción a la hermenéutica filosófica, Herder, Barcelona, 1999; Hernández-Pacheco, J. Corrientes actuales de filosofía. La escuela de Francfort. La filosofía hermenéutica, Tecnos, Madrid, 1996.

${ }^{30}$ Koselleck, R. Futuro Pasado..., Op. cit, pp. 105-173.

${ }^{31}$ Hölscher, L. "Los fundamentos teóricos de la historia de los conceptos (begriffsgeschichte)" en Olábarri, I.-Caspistegui, F. J. (dir.) La Nueva Historia Cultural..., Op. cit., pp. 69-82.

${ }^{32}$ Una visión global de estos autores puede verse en Palti, E., Giro Lingüístico e Historia Intelectual..., Op. cit.

${ }^{33}$ Austin, J. Cómo hacer cosas con palabras. Palabras y acciones, Gedisa, Barcelona, 1988.

${ }^{34}$ Pocock, J. Grenville Agard, Politics, Language, and Time. Essays on political thought and history, Athenaeum, New York, 1971; Skinner, Q., The foundations of Modern political thought, Cambridge University Press, Cambridge, 1978. (trad. cast.: Los fundamentos del pensamiento político moderno, F.C.E., México, 1986). 
investigador conocer las posibilidades de sentido de la obra y detectar los dispositivos argumentales que se diseñan. El lenguaje es en sí mismo un hecho político. Por ello, considera que no se puede separar el lenguaje de la acción, el lenguaje constituye una práctica. El tipo de enunciado que despliega un determinado actor social siempre reclama hechos políticos, ya que el hombre siempre está obligado a responder por sus palabras o, al menos, a dar cuenta de ellas, en el caso de los cínicos.

Estas tres tradiciones de teorías del lenguaje, constituyen un "fondo" teórico, en el cual la "nueva historia intelectual" diseña sus diferentes enfoques. Estas aproximaciones teóricas, en realidad, poseen interrelaciones permanentes y se desarrollan en espacios de diálogo entre ellas y aún, intra-ellas.

Los avances del denominado Linguistic Turn han abierto un debate específico que no podemos dejar de mencionar: esta polémica centra su atención en la relación Texto/ Contexto. Para algunos investigadores resulta primordial el contexto de producción en el cual se desarrolla y se nuclea el proceso de circulación de ideas ${ }^{35}$. La desventaja de este esquema radica en olvidar que las ideas son por sí mismas ahistóricas y que no siempre se "ajustan" a las diferentes estructuras apócales. Para otros, en contraste, las ideas nacen de los distintos niveles de los discursos que aparecen en la circulación en los textos y, por lo tanto, otorgan prioridad al estudio del libro como artefacto cultural generador de ideas ${ }^{36}$ (esto es, desde su soporte material hasta los filosófemas contenidos en él). La desventaja de dicho criterio metodológico estriba en considerar a las ideas como categorías abstractas o metahistóricas, encerradas en un lenguaje propio, desprendidas del componente socio-histórico.

Más allá de las discusiones planteadas por estos autores, que exceden la propuesta de este estudio, es necesario aclarar que la visión a tenerse en cuenta, desde nuestro punto de vista, puede resumirse en una complementariedad entre ambos enfoques analíticos. Es decir, se puede concebir un esquema que muestre la acción del "texto en el contexto". El estudio de una diversidad de documentos y obras nos puede dar la caracterización de los distintos lenguajes políticos utilizados y también otorgar ciertas nociones de cómo era el campo de producción. Evidentemente este juego de acción y reacción no es lineal ni homógeneo sino que se desenvuelve de una forma dinámica, laberíntica, con pliegues y repliegues.

En síntesis, el contexto emergente conformado por el Giro Lingüístico brinda al investigador la posibilidad de emplear categorías analíticas tales como <discursos>, $<$ conceptos $>$ y $<$ lenguajes $>$. Estas constituyen objetos de estudio que se articulan en distintos niveles interpretativos pero que, en última instancia, re-definen las nuevas metodologías y abordajes teóricos de la historia intelectual reciente. Por otro lado, también, la nueva historia intelectual propone en sus tres vertientes una fuerte crítica a la visión anterior que operaba casi exclusivamente sobre las grandes obras -sobre todo, los llamados clásicos-, para observar los contenidos allí establecidos en función de su continuidad con respecto al presente. A cambio, se propone reconstruir las

\footnotetext{
${ }^{35}$ Pocock, J. Grenville Agard, Op. cit.; Skinner, Q., Op. cit.

${ }^{36}$ White, H. El texto histórico como artefacto literario, Paidós, Barcelona, 2003.
} 
modalidades de enunciación y las formas en las cuales éstas se reproducen a través del lenguaje para abordar el estudio de las corrientes de pensamiento. De manera que se considera importante estudiar no sólo las obras canónicas, sino también los textos menos conocidos y establecer los puentes de contacto entre ese autor y otros autores, las intencionalidades y el contexto preciso en el cual estas obras circulan y dialogan entre sí.

\section{A modo de conclusión}

El "exceso de realidad" que sustentaba la historia intelectual tradicional provoca en la actualidad desde los nuevos lineamientos de la nueva historia intelectual un "exceso de abstracción". La reacción de la flamante historia intelectual produce en algunos casos un obstáculo al considerar a las ideas vaciadas de contenidos y desplegadas sólo a través de los contornos de sus actos comunicativos, como meras categorías lingüísticas aisladas de su contexto social. Sin embargo, la posible aproximación a tal aporía no es colocarse en un justo medio entre ambos abordajes. El desafío se bosqueja en buscar un espacio académico compartido que proponga miradas y debates abarcadores sobre las problemáticas complejas percibiendo distintos niveles argumentativos interconectados sin que ninguno de éstos se convierta en el modelo hegemónico.

Concibo que el abordaje de una historia intelectual enfocada exclusivamente desde la lingüisticalidad y desprendida del componente histórico-contextual se caracteriza por evidenciar un análisis demasiado estrecho $\mathrm{y}$, en algunos casos, artificioso. La nueva historia intelectual, que pone el acento en los estudios de los lenguajes, debería articularse desde una historia cultural o, si se prefiere, desde una historia de la cultura política. No puede perderse de vista que el lenguaje es un fenómeno de la cultura material y simbólica del hombre elaborado en distintas situaciones y a lo largo del tiempo. Los "momentos de enunciación" de los lenguajes, dispuestos en los diferentes niveles discursivos, son el reflejo de un proceso de apropiación por parte de los actores sociales que construyen "los sentidos" de sus prácticas culturales. En tanto, el lenguaje político como objeto de estudio remite necesariamente al hecho cultural, ya que es a partir del "uso" social del mismo por parte de una comunidad interpretativa el que éste otorgue una significación "generalizada" y "compartida".

Finalmente, un elemento interesante es que el nuevo enfoque de la historia intelectual permite comprender los cambios históricos en un sentido gradual en el desarrollo de las distintas concepciones y sus derivaciones con el mundo social. Es decir, enfocar el análisis sobre los lenguajes articula un proceso de historización en sí mismo. Otorga al investigador la posibilidad de observar los laberintos de la circulación de los discursos como puntos de ondulación de las sociedades en la conformación de sus prácticas e imaginarios políticos, siempre y cuando, se reconozca este proceso sinuoso en interacción con la experiencia histórica.

A pesar de los recelos académicos por la imposición de estas categorías en el uso corriente de la producción de obras históricas, es cierto que cualquiera sea el término 
utilizado se está en presencia de un conjunto de formas de pensamiento. Según, Carlos Altamirano, la historia intelectual debe entenderse como un campo de estudios abiertos, no una disciplina o subdisciplina de la historia ${ }^{37}$. En consecuencia, la historia intelectual se define dentro de los parámetros de la ciencia histórica, pero por su objeto de estudio mismo, se encuentra en un límite, reviste y considera necesariamente la articulación con otras ciencias humanas.

${ }^{37}$ Altamirano, C. Para un programa de historia intelectual y otros ensayos, Siglo Veintiuno Editores, Buenos Aires, 2005. 